\title{
DEUTSCHE SCHULE URBANA - COLLEGIO ALLEMÃO DE PELOTAS NA ROTA DA VEREIN FÜR DAS DEUTSCHTUM IM AUSLAND (V.D.A.), 1921-1925, 1933
}

\author{
Maria Angela Peter da Fonseca* \\ lattes.cnpq.br/3146965417557221 \\ Elomar Antonio Callegaro Tambara ${ }^{* *}$ \\ lattes.cnpq.br/5731658342862947
}

\begin{abstract}
Resumo: Neste artigo enfoca-se o papel dos visitantes que chegavam à Deutsche Schule urbana, Collegio Allemão de Pelotas, no sul do Rio Grande do Sul, provenientes da Verein für das Deutschtum im Ausland (V.D.A.), (Sociedade de Apoio ao Deutschtum no Exterior), em 1921, 1923, 1924, 1925 e 1933, situada em Hamburgo e Berlim, na Alemanha. O objetivo desses visitantes era inspecionar o projeto educacional alemão e a manutenção do Deutschtum, que mesclava elementos do nacionalismo alemão, vigente, à cultura escolar deste educandário em tempos de Nacionalização do Ensino no Brasil. Consequência dessas visitas era o envio de livros, material didático e professores alemães, bem como a troca de correspondência entre os alunos do educandário de Pelotas e alunos alemães. Trata-se de pesquisa qualitativa, bibliográfica e documental cujas fontes principais são os Relatórios Escolares da Deutsche Schule de Pelotas dos anos 1921, 1923, 1924, 1925 e 1933.
\end{abstract}

Palavras-chave: instituição escolar, função de inspeção, projeto pedagógico, herança cultural.

\section{URBAN DEUTSCHE SCHULE - GERMAN COLLEGE OF PELOTAS ON THE VEREIN FÜR DAS DEUTSCHTUM IM AUSLAND (V.D.A.) ROUTE, 1921-1925, 1933}

\begin{abstract}
This paper focuses on the role of visitors arriving at the urban Deutsche Schule, German College of Pelotas, in the south of Rio Grande do Sul from the Verein für das Deutschtum im Ausland (VDA), a Society for Supporting Deutschtum Abroad, in 1921, 1923, 1924, 1925 and 1933, located in Hamburg and

\footnotetext{
* Doutora em Educação pela Universidade Federal de Pelotas, UFPel (Brasil). Contato: mpeterdafonseca@gmail.com.

** Doutor em Educação. Docente na Universidade Federal de Pelotas, UFPel (Brasil). Contato: tambara@ufpel.edu.br.
} 
Berlin, Germany. The purpose of these visitors was to inspect the German educational project and the maintenance of the Deutschtum, which merged elements of German nationalism, in force, into the school culture of this educandário in times of Nationalization of Teaching in Brazil. The consequence of these visits was the sending of books, didactic material and German teachers, as well as the exchange of correspondence between the students of the educator of Pelotas and German students. It is a qualitative, bibliographical and documentary research whose main sources are the School Reports of the Deutsche Schule of Pelotas of years 1921, 1923, 1924, 1925 and 1933.

Keywords: School institution; Inspection function; Pedagogical project; Cultural heritage.

\section{Introdução}

Neste artigo enfoca-se o papel dos visitantes que chegavam à Deutsche Schule (Escola Alemã) urbana, denominada Collegio Allemão de Pelotas, no sul do Rio Grande do Sul, em 1921-1925, 1933, provenientes da Verein für das Deutschtum im Ausland (V.D.A.), (Sociedade de Apoio ao Deutschtum no Exterior), situada em Hamburgo e Berlim, na Alemanha. Trata-se de pesquisa qualitativa, bibliográfica e documental, cujas fontes principais são os Relatórios Escolares da Deutsche Schule de Pelotas dos anos 1921, 1923, 1924, 1925 e 1933, localizados na Deutsche Bücherei ${ }^{1}$, em Leipzig, Alemanha. Estas visitas visavam inspecionar o projeto educacional alemão e a manutenção do Deutschtum², que mesclava elementos do nacionalismo alemão,

\footnotetext{
${ }^{1}$ Deutsche Bücherei significa Biblioteca Alemã, que está localizada na cidade de Leipzig, Saxônia, Alemanha.

${ }^{2}$ Grützmann (2003), define Deutschtum como uma combinatória de múltiplas ideias de filósofos e pensadores alemães que contribuíram para a formação da nação alemã e da constituição de um ethos genuinamente alemão, no século XIX. Núñes Seixas (1994) ressalta que Deutschtum é um termo que aponta para várias
} 
vigente, à cultura escolar dessa Deutsche Schule, em tempos de Nacionalização do Ensino no Brasil.

Assim, para compreender a cultura escolar deste educandário, buscam-se referenciais na História Cultural que é uma modalidade de pesquisa historiográfica que conjuga duas abordagens opostas que procuram entrar em acordo (BURKE, 2008). Uma interna, que busca aspectos mais amplos, abarcando artes do passado, tentando superar as fragmentações atuais da disciplina; e outra, externa, associada a uma visão de fora, vinculada a uma virada cultural, direcionando interesses para "grupos particulares em locais e períodos específicos" (BURKE, 2008, p. 8), como é o caso em estudo.

Sob o ponto de vista da História Cultural, perscrutamos a cultura escolar, aferindo aspectos internos e externos. Julia (2001), ao descrever cultura escolar como "um conjunto de normas que definem conhecimentos a ensinar e condutas a inculcar, e um conjunto de práticas que permitem a transmissão de conhecimentos e a incorporação de comportamentos", elucidou dois lados da instituição escolar, que coexistem entre as normas e as práticas, visíveis ou não, vinculadas a objetivos que podem mudar de acordo com as épocas, tais como: objetivos religiosos, sociopolíticos ou de socialização. O autor afirma que, o entendimento da cultura escolar, perpassa pela análise das "relações conflituosas ou pacíficas que ela mantém, a cada período de sua história, com o conjunto das culturas que lhe são contemporâneas: cultura religiosa, cultura política ou cultura popular" (JULIA, 2001, p. 10).

Conforme o autor, as normas, como diretrizes externas à escola, definem o que poderá ser ensinado e que habitus poderá ser inculcado e deveriam remeter às práticas. No que diz respeito às práticas, que circulam no interior da escola e, que não deixam rastros, deveriam corresponder às diretrizes que elegem os conhecimentos que serão transmitidos e os comportamentos que serão incorporados. Julia (2001) postula que tanto as normas como as práticas precisam ser

significados, entre eles, político, étnico e linguístico, em uma relação, às vezes, sobreposta, de difícil sincronia. 
analisadas levando em consideração o corpo docente da instituição, o qual deve observar essas ordens e usar aparatos didático- pedagógicos para viabilizar a sua aplicação.

Nesse sentido, "a cultura escolar é efetivamente uma cultura conforme (grifo do autor), e seria necessário definir, a cada período, os limites que traçam a fronteira do possível e do impossível" (JULIA, 2001, p. 32). Desta forma, é neste intermezzo, entre a recepção do cânone e a sua aplicação, mais propriamente, na sua execução - com o desempenho do papel do professor que recebe, lê, interpreta e transmite os conhecimentos para um corpo discente - que se produzem práticas escolares em suas inúmeras formas de expressão.

\section{A Deutsche Schule urbana Collegio Allemão de Pelotas e a Verein für das Deutschtum im Ausland (V.D.A.) (Sociedade de Apoio ao Deutschtum no Exterior)}

O recorte temporal contemplado neste estudo corresponde a um intervalo temporal que se encontra entre as duas guerras mundiais 1921-1925 e 1933, quando então, o Brasil caracterizava-se como uma nação jovem, que dava seus primeiros passos como República, e precisava de um sistema de ensino que definisse a sua identidade nacional (PAIVA, 1973; REIS FILHO, 1981; RIBEIRO, 1995; NAGLE, 2001; SAVIANI, 2002). Sob esta perspectiva, a campanha de Nacionalização do Ensino foi propícia e permeou este período de ponta a ponta, intensificando seu projeto por ocasião da Segunda Guerra Mundial. Porém, o Rio Grande do Sul, sob a égide do Partido Republicano RioGrandense, neste ponto, divergia do poder central, e apesar de fundar inúmeras escolas públicas, também apoiou as escolas de imigrantes, no caso, alemães. Esta situação foi favorável à criação de inúmeras escolas desta natureza em solo rio-grandense.

A cidade de Pelotas, instalada no pampa da região sul do Rio Grande do Sul, não ficou alheia a estas circunstâncias. Convém lembrar que Pelotas era passagem obrigatória para a capital Porto Alegre, 
bem como era de fácil acesso às regiões platinas, como o Uruguai e a Argentina, tanto por via lacustre, pela Lagoa Mirim, como através do porto marítimo do Rio Grande. Egressa do ciclo do charque, cujo apogeu foi no século XIX (MAGALHÃES, 1993), constituiu-se em metrópole comercial devido à sua localização estratégica e privilegiada, na esteira da industrialização e modernização do estado do Rio Grande do Sul que visava a formação do cidadão rio-grandense dos novos tempos do capitalismo, sob a ótica do castilhismo (CORSETTI, 1998).

Com uma população urbana predominantemente luso-brasileira, teve o fortalecimento deste status, principalmente devido à chegada de estrangeiros, como alemães, italianos, franceses, ingleses, uruguaios, espanhóis e portugueses (ANJOS, 2000; LONER, 2001). Entre as fábricas fundadas e administradas por imigrantes alemães e descendentes, no perímetro urbano de Pelotas, de meados do século XIX em diante, com uma produção diversificada, elencam-se, as seguintes: fábrica de velas e sabonetes de Frederico Carlos Lang; fábrica de sabonetes de R. Neumann; fábrica de chapéus de W. Wiener, Spanier e Rheingantz; fábrica de cerveja de Carlos Ritter; fábrica de cerveja de L. Härtel; fábrica de cola de F. Müller; fábricas de fumo de Jakob Klaes; fábrica de couros envernizados de Guilherme Sieburger; e a fábrica de curtume de Henrique João Hadler e Germano Feichert (ANJOS, 2000; SIMON, 1938). Concomitantemente, em Pelotas, destacam-se a casa comercial Ferragem Warncke \& Dörken, de Francisco Behrensdorf (ANJOS, 2000). Em relação às casas comerciais, representantes de firmas rio-grandenses e porto-alegrenses, citam-se: Luchsinger \& Cia.; Thomsen \& Cia.; Fräb, Nieckele \& Cia.; Fräb \& Cia.; C. Albrecht \& Cia.; Das Haus Wachtel e Marren \& Cia. (SIMON, 1938). Ferragem Warncke \& Dörken, de Francisco Behrensdorf (ANJOS, 2000).

No que diz respeito à educação, esta pequena burguesia étnica formada por imigrantes alemães e descendentes urbanos, ligados à indústria e ao comércio em Pelotas, fundou, no final de 1898, uma Sociedade Escolar Alemã (Deutscher Schulverein) que deu origem à Deutsche Schule, urbana denominada Collegio Allemão de Pelotas. A 
maioria dos membros dessa sociedade mantenedora e administradora dessa escola fazia parte da Comunidade Evangélica Alemã de confissão luterana (Deutsche Evangelische Gemeinde) fundada em 1888. No entanto, na zona rural de Pelotas, os imigrantes pomeranos eram hegemônicos e fundaram numerosas escolas de ensino primário (KOLLING, 2000).

A Deutsche Schule urbana Collegio Allemão de Pelotas era uma escola de ensino primário e secundário, que funcionou durante 44 anos em Pelotas (1898-1942), onde estudavam crianças filhas de imigrantes alemães e descendentes, mas também havia um número significativo de alunos luso-brasileiros e alguns de outras nacionalidades (como suíça, tcheca, holandesa e inglesa). Apesar de não ser uma escola confessional, a religião da maioria dos alunos era a evangélica de confissão luterana. Os professores eram predominantemente alemães ou descendentes de alemães, sendo a maioria com formação em magistério na Alemanha. Nesta Deutsche Schule havia um duplo currículo: alemão e brasileiro. Na realidade era uma escola alemã situada em solo brasileiro que seguia um currículo alemão com o acréscimo do Português, da Geografia do Brasil e da História do Brasil, disciplinas ministradas, exclusivamente por professores brasileiros, cumprindo as leis educacionais do Brasil, no estado do Rio Grande do Sul.

Através da análise dos Relatórios Escolares da Deutsche Schule urbana Collegio Allemão de Pelotas (1921, 1923, 1924, 1925 e 1933), verifica-se que sujeitos provenientes da Verein für das Deutschtum im Ausland V.D.A., (Sociedade de Apoio ao Deutschtum no Exterior), localizada em Hamburgo e Berlim, na Alemanha, visitaram com relativa assiduidade este educandário em alguns anos das décadas de 1920 e 1930. Há que se ter em conta que a Deutsche Schule urbana Collegio Allemão de Pelotas visava uma educação escolar alemã, pautada no Deutschtum, destinada, preferencialmente, aos descendentes étnicos que permaneceriam no Brasil. E esta educação fazia parte de um projeto vinculado ao V.D.A., inicialmente ligado ao império alemão, como uma forma de assistir aos alemães emigrados, estendendo-se à 
República de Weimar e à ascensão do Nacional Socialismo na Alemanha, alinhando-se às distintas propostas do nacionalismo alemão.

Com a extinção do Império Alemão, em consequência do término da Primeira Guerra Mundial, foi proclamada a República de Weimar (1919-1933). A proposta republicana alemã manifestou-se através da Constituição de Weimar que anunciava a reconstrução de uma Alemanha que havia sido derrotada, com perdas de territórios e consequentemente de um grande número de alemães que passou a integrar outras nações, sem, no entanto deixarem de ser alemães. Este quesito mobilizou a atenção de autoridades alemãs, religiosos, estudiosos e leigos que fomentaram a criação de inúmeras sociedades de apoio ao Deutschtum no exterior. Muitas dessas sociedades tiveram suas origens ainda no período do império alemão. É preciso levar em consideração que o cuidado dessas sociedades com o Deutschtum difundiu-se sob diferentes vieses, principalmente cultural, educacional, por vezes, religioso, bem como político.

Durante o Segundo Império da Alemanha (1871-1914), a manutenção do Deutschtum, entre os alemães e descendentes no exterior, teve como matriz o conceito de nação étnica permeado pela cultura e a língua alemã (ARENDT, 2011). Além do estado alemão, também participaram, desse projeto, associações de alemães no exterior, organizações imperiais e as igrejas, que fomentaram as inúmeras escolas de língua alemã na América Latina (RINKE, 1996). A função primordial dessas escolas era a preservação da língua alemã. Mas junto a esta função vinha a manutenção de um arcabouço teórico e cultural eivado de elementos do nacionalismo alemão.

Núñes Seixas (1994), cita duas organizações de apoio ao Deutschtum no exterior, fundadas no período do império alemão. A organização Allgemeine Deutsche Schulverein zur Erhaltung des Deutschtums im Ausland (Sociedade Escolar Alemã Geral para a Preservação do Deutschtum no Exterior), fundada em 1881, que, em 1908, passou a ser denominada Verein für das Deutschtum im Ausland, conhecida como V.D.A. (Sociedade de Apoio ao Deutschtum no Exterior). Essa organização transitava precipuamente na esfera cultural, 
com vistas a auxiliar na fundação de escolas e bibliotecas alemãs, assim como o fornecimento de livros alemães, indicação e apoio a professores alemães, com o intuito de manter o Deutschtum dos alemães no exterior. E a Alldeutsche Verband (Liga Pan-Alemã), fundada em 1891, de cunho político, numa linha conservadora, que objetivava a união de todos os alemães, quer em território imperial, quer em assentamentos no exterior.

Como se pode perceber, as atividades de expansão da Verein für das Deutschtum im Ausland, V.D.A., deveriam ater-se ao nível cultural: defesa e promoção da cultura alemã e do sentimento de pertença ao Deutschtum, ou seja, à uma comunidade nacional comum. Para atingir tal objetivo era necessário que os limites políticos tanto da Alemanha como dos outros Estados, não colocassem barreiras para a ampliação do sentimento nacional dos alemães no exterior. Nesta direção propalava-se a autonomia cultural, defendendo-se o direito de cultivar a língua alemã, através da qual seriam mantidos os laços culturais com a Alemanha (denominada Mutterland - terra mãe). Segundo Wertheimer (1927), o fato de se permitir a conservação dos caracteres nacionais originais no campo intelectual, de certo modo, oportunizava uma autonomia que poderia transcender o nível cultural (NÚÑES SEIXAS, 1994), e apresentar distintos matizes, de acordo com o nacionalismo vigente, respectivamente, do final do Império Alemão, da República de Weimar, ou do início do Nacional Socialismo.

Durante a Primeira Guerra Mundial (1914-1918), a Deutsche Schule Collegio Allemão de Pelotas, manteve-se em funcionamento, inicialmente sob a direção do professor André Gaile que, no final de 1915, transferiu sua função para o professor Reinhard Heuer, que permaneceu até 1925. Neste período a escola diminuiu substancialmente o número de alunos, tornando-se um local de proteção aos pares em função do estigma social deferido ao grupo étnico. Assim, o projeto de educação alemão procurou ajustar-se aos cânones brasileiros, intensificando o ensino em língua portuguesa, apesar da manutenção da língua alemã. 
A instituição de Pelotas era administrada pela Sociedade Escolar Alemã que despendia esforços imensos para manter o educandário. Há que lembrar que na década anterior, ainda durante o Império Alemão, a escola recebia auxílio financeiro de pessoas físicas e jurídicas de vários lugares do mundo, como a Alemanha, Hungria, República Tcheca (Relatório, 1913) e, especialmente, da mencionada sociedade, sempre atenta para suprir as necessidades da instituição.

Na década de 1920, a Deutsche Schule Collegio Allemão de Pelotas, de acordo com o mencionado anteriormente, recebeu vários visitantes provenientes da Alemanha, ligados a Verein für das Deutschtum im Ausland (V.D.A.), (Sociedade de Apoio ao Deutschtum no Exterior), de cunho cultural e/ou religioso. Há que se ponderar que, no período pós Primeira Guerra Mundial aconteceu um movimento de reerguimento da cosmovisão que tinha como propósito a implantação do espírito alemão como uma meta a ser atingida não somente na Alemanha, propriamente dita, mas também e, talvez, principalmente nas comunidades alemãs no exterior. As consequências da guerra feriram fortemente a autoestima das comunidades que viram de uma hora para outra ruírem muitos dos esteios socioculturais que as sustentavam. Particularmente a ideia de uma supremacia consubstanciada em um tipo de comportamento, como obstinação, trabalho, fé, cultura entre outros, ditos como especiais, não se confirmou na prática. De modo que o que ocorreu foi a intensificação de um processo de propaganda e mesmo de ressignificação destas características nos mais diferentes aparelhos ideológicos da sociedade. E neste sentido o aparelho escolar, como vimos, constituiu-se em um locus privilegiado.

Mas este processo precisava de modo geral ser tutelado pela matriz - a Alemanha. Havia um modelo a ser aplicado. E é este comportamento que explicava as frequentes visitas que a Deutsche Schule urbana Collegio Allemão de Pelotas recebia. Tanto que nos relatórios era muito ressaltada a boa avaliação que estas inspeções proporciona- 
vam. Havia aqui um trajeto de duas vias, pois um bom comportamento permitia que as instituições alemãs fossem mais generosas em suas contribuições, principalmente as de caráter financeiro.

Tais condições podem ser apreendidas nos Relatórios de $1921 \mathrm{e}$ 1925 .

Agradecemos a honra de termos recebido as seguintes visitas durante este ano: Sr. Dr. Borchard, Sr. Professor Dr. Grosscurth e o Sr. Diretor Dr. Timpe, todos de Hamburgo. Os dois últimos cavalheiros, membros da diretoria da Verein für das Deutschtum im Ausland, conhecida como V.D.A. (Sociedade de Apoio ao Deutschtum no Exterior), do grupo local de Hamburgo. Agradaram-nos particularmente por sua compreensão das nossas peculiares condições escolares em Pelotas. [...]. A escola recebeu 62 volumes de obras maiores e menores da Sociedade de Apoio ao Deutschtum no Exterior, de Berlim, do Departamento de Biblioteca e Arquivos (RELATÓRIO, 1921, p. 7, 8)3. [...] Nós também recebemos diferentes doações da Sociedade de Apoio ao Deutschtum no Exterior (RELATÓRIO, 1925, p. 11).

Evidentemente havia uma forte expectativa em relação a estas frequentes visitas e das quais resultavam, muitas vezes, a manutenção dos laços de contribuição financeira da qual, por vezes, a instituição escolar era bastante dependente. Ademais, havia necessidade do atestado de que as práticas pedagógicas coadunavam com as exigidas pelas agências alemãs que trabalhavam com as escolas alemãs no exterior. Como pode-se perceber no Relatório de 1925:

Gostaríamos que estas visitas tenham sido úteis para nossa escola, não somente fortalecendo os laços de união da colô-

3 Für die Ehre ihres Besuches haben wir in diesem Jahre zu danken: Herrn Dr.Borchard, Herrn Professor Dr. Grosscurth und Herrn Direktor Dr. Timpe, sämtlich aus Hamburg. Die beiden letztgenannten Herren, Vorstandsmittglieder des Vereins für das Deutschtum im Ausland, Ortsgruppe Hamburg, erfreuten uns besonders durch das verständnisvolle Eingehen in unsere eigenartigen Schulverhältnisse im Pelotas. [...]. Vom Verein für das Deutschtum im Ausland, Berlin, Abteilung für Bücherei und Archiv, erhielt die Schule 62 Bände grösserer und kleinerer Werke (JAHRESBERICHT, 1921, s. 7, 8). [...] Auch vom Verein für das Deutschtum im Ausland erhielten wir verschiedentliche Spenden (JAHRESBERICHT, 1925, s. 11). 
nia alemã local, manifestados na alegria festiva dos nascidos na Alemanha durante a visita dos enviados, mas também chamamos a atenção para que apoiem o antigo pensamento e a sensibilidade alemãs que são essenciais para a escola alemã (RELATÓRIO, 1925, p. 5)4.

O projeto envolvia interesses de âmbito mundial. No caso da Deutsche Schule urbana Collegio Allemão de Pelotas, essa era apenas uma peça em uma engrenagem. Mas em decorrência da importância da cidade em termos geopolíticos essa recebeu importante atenção das agências alemãs preocupadas com o processo de expansão e consolidação do Deutschtum no exterior. Particularmente havia uma preocupação com a qualidade do ensino e de modo especial em relação ao domínio da língua alemã, evidenciado no Relatório de 1924.

A escola alemã encerrou o ano escolar com 76 alunos. Como pode ser visto a partir dos relatórios estatísticos, apenas 8 alunos não falam a língua alemã. Esses 8 alunos, não vieram para a nossa escola para aprender apenas a língua alemã, mas desejavam aumentar e consolidar seus conhecimentos gerais que não tinham nas escolas que haviam frequentado até agora (RELATÓRIO, 1924, p. 5)5.

Neste período, essas sociedades propagavam-se na República de Weimar (Nuñes Seixas, 1994) e as Deutsche Schulen (Escolas Alemãs), situadas no exterior, guardiãs da língua alemã, eram a menina dos olhos das citadas sociedades, especialmente da V.D.A. E uma das estratégias para dimensionar, inspecionar e conferir até que

4 Möchte dieser Besuch nutzbringend für unsere Schule sein, den Zusammenschluss der deutschen Kolonie inniger werden lassen und jenen Deutschbürtigen, die na der Festesfreude des Gesandtenbesuches teilnahmen, sonst aber abseits stehen, in Gedächtnis rufen, dass zur Erhaltung alt-deutscher Denk- und Gefühlsart die Unterstützung der Deutschen Schule unerlässlich ist (JAHRESBERICHT, 1925, s. 5).

5 Die Deutsche Schule wurde im verflossenen Schuljahre von 76 Schülern resp. Schülerinnen besucht. Wie aus den statistischen Mitteilungen ersichtlich, beherschten nur 8 Schulkinder nicht die Deutsche Sprache. Diese 8 Schüler bezw. Schülerinnen traten nicht in unsere Schule, um nur deutsch zu lernen, sondern sie sollten in erster Linie ihre allgemeinen Kenntnisse vermehren und befestigen, wozu sie in den von ihnen bisher besuchten Schulen nicht gekommen waren (JAHRESBERICHT 1924, s. 5). 
ponto o projeto educacional alemão pautado pelo Deutschtum prosperava no sul do Rio Grande do Sul, no caso, em Pelotas, foi o envio de visitantes, a esse educandário. Concomitante a essas visitas chegavam doações de livros e materiais didáticos, bem como professores e na década de 1930 foi incentivada a correspondência entre alunos brasileiros e alemães.

A Deutsche Schule urbana Collegio Allemão de Pelotas procurou constituir-se em um espaço de socialização que conciliasse os vários projetos sociais em disputa, mas sempre tendo como premissa principal o objetivo de difundir o espírito alemão. Neste clima de expectativa de um futuro melhor e nostalgia e saudade de um passado, o diretor Reinhard Heuer roga aos leitores do Relatório de 1921, que recordem a velha pátria alemã e se irmanem ao desejo de sua reedificação, fazendo jus às virtudes alemãs como a lealdade, a coragem e o sentido do dever. E reforça seu pedido com as seguintes palavras: "Do conhecimento do que era a Alemanha, e do que deve ser, surge o lembrete de Goethe: 'O que você herdou de seus pais, adquira para possuí-lo’" (RELATÓRIO, 1921, p. 3)

O diretor também dirige palavras de coragem e ânimo aos alunos lembrando-os a honrarem a herança de seus antepassados: seus nomes alemães, com sua postura diante do mundo, do país que os acolhe e, que, concomitantemente, não neguem suas origens, independente de quaisquer circunstâncias. $O$ professor fala aos alunos da Deutsche Schule urbana Collegio Allemão de Pelotas, na condição de estrangeiro em terras brasileiras e, sob o ponto de vista alemão, os alunos que aqui estudam, estão no estrangeiro. Essa situação reflete, nitidamente, um projeto educacional alemão no sul do Rio Grande do Sul, com vistas à expansão do espírito da nação alemã.

Para que o nome alemão recupere o seu bom e antigo som no mundo, os nossos alunos, no estrangeiro, terão um duplo dever: 1. Trabalhem! De modo que vocês estejam tão

${ }^{6}$ Aus der Erkenntnis dessen, was Deutschland war, und was es wieder werden soll und kann, ergibt sich die Mahnung: "Was du ererbt von deinen Vätern has, erwirb es, um es zu besitzen (JAHRESBERICHT 1921, s. 3). 
bem equipados com conhecimento e habilidade que vocês vão honrar o nome alemão com suas realizações! 2. Sejam orgulhosos de sua descendência alemã, apesar de tudo! (RELATÓRIO, 1921, p. 3)7.

O diretor reconhece que, aqui no Brasil, os alemães e descendentes, gozam da hospitalidade de um povo grande e livre e, considera-se feliz por isso e, grato por observar e respeitar as exigências legais do país. Acrescenta que os alemães nascidos no Brasil, são brasileiros e, ao conviverem com duas nacionalidades, conciliam o amor à pátria brasileira, com o amor à velha pátria de seus antepassados. Assim justifica seu pensamento, dizendo: "E se o grande poeta brasileiro Olavo Bilac diz: 'ser brasileiro é cumprir os seus deveres', consideramos um dos deveres nobres honrar os pais e os antepassados e com eles o país de onde se originaram" (RELATÓRIO, 1921, p. 2)8.

Nesta via, os alemães brasileiros, transitam numa senda entre o passado e o presente e formam uma identidade peculiar, acrescida da angústia no futuro, da pátria de suas origens. Vivem uma realidade psicológica complexa devido ao tensionamento das diversas temporalidades e suas respectivas conjunturas às quais têm acesso. Na verdade se os descendentes não preservarem este passado, através da língua alemã e da educação que se dá na escola, no caso, na Deutsche Schule urbana Collegio Allemão de Pelotas, a densidade dessa memória se diluirá e seu sentido se esvaziará pouco a pouco. Mas a isso estavam associados outros motivos, que reverberavam a questão do nacionalismo, aos moldes da República de Weimar, na reconstrução

\footnotetext{
7 Soll aber der deutsche Name seinen guten alten Klang in der Welt wieder gewinnen, so erwächst unsern Schülern im Ausland eine doppelte Pflicht: 1. Arbeitet! Damit ihr an Wissen und Können so ausgestattet seid, dass ihr dem deutschen Namen durch euere Leistunge Ehre macht! 2. Seid trotz Allen stolz auf eure deutsche Abstammung! (JAHRESBERICHT, 1921, s. 3).

8 Und wenn der grosse brasilische Dichter Olavo Bilac sagt: "ser brasileiro é cumprir os seus deveres", so halten wir es für eineder vornehmen Pflichten, die Eltern und Vorfahren in Ehren zu halten und mit ihnen das Land, aus dem sie hervorgegangen sind (JAHRESBERICHT, 1921, s. 2).
} 
alemã no pós Primeira Guerra Mundial, que transcendia a preservação do Deutschtum em nível cultural.

No ano de 1923, a Deutsche Schule urbana Collegio Allemão de Pelotas, completou 25 anos de atividade (RELATÓRIO, 1923), e esse relatório, foi impresso em maior número, para que abrangesse, não somente os membros da Sociedade Escolar Alemã, mas também outros círculos teuto-brasileiros de Pelotas, com vistas a anunciar, divulgar e promover a instituição e, especialmente o Deutschtum. A Deutsche Schule urbana Collegio Allemão de Pelotas, oferecia a seus alunos a oportunidade do ensino em dois idiomas: em língua alemã e em língua portuguesa. Segundo o diretor, na escola, as crianças convivem com outras crianças e se comunicam na língua do país, porém nas famílias o idioma da comunicação deveria ser a língua alemã. A situação nem sempre era assim e muitos pais agravavam ainda mais o problema ao ensinarem incorretamente a língua alemã a seus filhos, o que os prejudicava ainda mais. Com o intuito de mostrar aos pais, o valor da língua alemã, o diretor acrescenta as palavras do professor Dr. Owen do Seminário de Formação de Professores de Chicago, EUA. O citado professor recomenda a todos o aprendizado ou a preservação da língua alemã, justificando que o seu conhecimento é inestimável nos campos da ciência, indústria, tecnologia e organização social.

No relatório do ano seguinte, comparando os alunos das escolas alemãs no exterior - no caso, os da Deutsche Schule urbana Collegio Allemão de Pelotas - com a mesma idade e nível escolar, com alunos das escolas na Alemanha, o diretor enfatiza que, preponderantemente, deve-se levar em consideração "que os nossos filhos aprendem, desde o primeiro ano de escolaridade, a se expressar em dois idiomas” (RELATÓRIO, 1924, p. 2, 3)99. Prova disso é que o primeiro ano tem um professor exclusivo. E considera que não é possível fazer uma transferência de métodos e objetivos sem adaptá-los às condições locais. "Por esta razão, também é impossível para os professores,

9 [...] dass unsere Kinder vom ersten Schuljahre an lernen, sich in zwei Sprachen auszudrücken (JAHRESBERICHT, 1924, s. 2, 3). 
que vêm da Alemanha para cá, simplesmente transferirem as condições alemãs para nossas escolas. Eles têm de se adaptar às nossas circunstâncias; caso contrário, uma falha ocorrerá mais cedo ou mais tarde" (RELATÓRIO, 1924, p. 3) ${ }^{10}$.

O discurso do diretor pode ser analisado sob dois pontos de vista. A partir da avaliação do desempenho dos dois professores alemães dentro da instituição, que pode ter sido favorável, ou não, à diretoria da Sociedade Escolar Alemã e à comunidade escolar. E sob o ponto de vista das leis educacionais brasileiras, ao reiterar a adaptação de métodos e objetivos de ensino. O diretor como porta voz de uma instituição de cunho étnico, alerta para as consequências que, a não observância da adaptação dos métodos e objetivos, poderão trazer "mais cedo ou mais tarde" (RELATÓRIO, 1924, p. 3)11.

Junto às observações de cunho pedagógico, o diretor agradece as visitas dos pastores: E. Hübbe, de Hamburgo; Gottschald, de Porto Alegre; e do senhor Schulrat a. D. Böttner, de Porto Alegre. Como se pode perceber, a escola continuava recebendo visitas da Alemanha, desta vez, de cunho religioso (RELATÓRIO, 1924).

Em sua mensagem aos pais, o diretor apresenta subsídios para pensar a complexa situação dos alunos luso-brasileiros dentro da instituição. Em conformidade com a Diretoria da Sociedade Escolar Alemã e seus estatutos, o objetivo da escola era

o de implantar por intermédio da instrucção subministrada nos idiomas allemão e do Paiz, os costumes da pátria e sua intenção, como também de preparar seus discípulos até o necessário grau para a realisação de seus direitos de cidadão e conhecimentos profissionaes na nova pátria. [..] o ensino constará, portanto, dos dois idiomas, até o completo conhecimento dos mesmos. [...] A instrução do idioma do Paiz será confiada a um lente de línguas

\footnotetext{
${ }^{10}$ Aus diesem Grunde aber ist es auch unmöglich, dass Lehrer, die aus Deutschland nach hier übernommen werden, einfach deutsche Verhältnisse in unsere Schulen übertragen wollen. Sie müssen sich vielmehr unseren Verhältnissen anzupassen suchen, sonst muss früher oder später ein Misserfolg gezeitigt werden (JAHRESBERICHT, 1924, s. 3).

${ }_{11}[\ldots .$.$] früher oder später (JAHRESBERICHT, 1924, s. 3).$
} 
(ESTATUTOS DO COLLEGIO ALLEMÃO DE PELOTAS, 1915).

Dentro desta perspectiva seria viável aprovar o desejo dos pais luso-brasileiros de que seus filhos fossem atendidos em uma turma específica. O diretor considerava isso possível, se os alunos fossem da mesma idade. De certo modo, isso facilitaria o andamento do ensino, mantendo a proposta da instituição. Mas, como eram alunos, com idades diferenciadas, entre 7 e 15 anos, a alternativa era a inserção em turmas individuais, o que causava um certo descompasso no ritmo do ensino, especialmente nas turmas em que o professor não dominava plenamente a língua portuguesa. Mas, o diretor afirma que a presença deles não poderia ser relegada, uma vez que eles contribuíam substancialmente com suas mensalidades. E reiterava que "essa era uma questão que merecia ser analisada com mais atenção” (RELATÓRIO, 1924, p. 5) $)^{12}$.

Depreende-se das palavras do diretor que este impasse demonstrava que, apesar da proposta original da escola, do ensino em dois idiomas, essa asserção requeria uma metodologia adequada para o acolhimento de alunos, especialmente, os do país em que estava localizada a escola alemã. A partir desses dados, questiona-se, por que os pais luso-brasileiros, inseridos em uma região predominantemente luso-brasileira, com dezenas de escolas brasileiras à disposição, colocavam seus filhos em uma instituição de cunho étnico alemão, com uma cultura absolutamente diferente da deles?

$\mathrm{O}$ diretor dá prosseguimento à sua reflexão e explana sobre os objetivos da escola alemã no exterior (RELATÓRIO, 1924). Em relação aos objetivos da escola alemã no exterior é voz corrente que ela deve ser uma imagem fiel das escolas localizadas na Alemanha, e estar a serviço dos interesses de um grupo particular, o que, evidentemente, não é bem visto pelas autoridades escolares brasileiras. $\mathrm{O}$ diretor apresenta exemplos de locais, especialmente na

12 [...] „so ist es unseres Erachtens angebracht, diese Seite unseres Schullebens ausführlicher zu behandeln, als sonst üblich war“ (JAHRESBERICHT, 1924, s. $5)$. 
zona rural, no interior do Rio Grande do Sul e Santa Catarina, em que os alunos falavam somente o idioma alemão, promovendo um isolamento cultural e social de graves consequências. O entendimento do diretor Reinhard Heuer é contrário ao pensamento do senso comum, e afirma que "uma escola estrangeira, puramente alemã, portanto, não é adequada para nós, mas sim rejeitada de forma bastante incisiva" (RELATÓRIO, 1924, p. 6) ${ }^{13}$. E tece considerações a respeito de a continuidade dessas escolas em território brasileiro estar diretamente relacionada ao cumprimento das leis nacionais de ensino do Brasil. Nada mais justo do que o governo brasileiro exigir que os alunos dessas escolas aprendam corretamente a Língua Portuguesa, a História e a Geografia do Brasil. Nesse sentido, afirma que o ensino e a educação desenvolvidos na Deutsche Schule Collegio Allemão de Pelotas não têm o objetivo de educar seus alunos para a Alemanha, uma vez que "Eles precisam construir suas vidas, mais cedo ou mais tarde, aqui no Brasil. Poucos têm condições de realizar seus estudos na antiga pátria alemã. Assim, quase sem exceção, nossos alunos construirão seu futuro no Brasil” (RELATÓRIO, 1924, p. 6) ${ }^{14}$.

Segue-se que a escola alemã não pode educar seus alunos
para a cidadania alemã, apesar de serem membros do Reino
Alemão15, uma vez que a maioria dos alunos nasceu no
Brasil e aí permanecerá. Qualquer um que queira ter tal
educação deve enviar seus filhos para a Alemanha, em uma
idade jovem [...]. A escola alemã no Brasil só pode educar
os futuros cidadãos brasileiros, assim como a escola
puramente brasileira, mas também lhes dá o legado do

13 Eine rein Deutsche Auslandschule ist daher für uns nicht geeignet, vielmehr ganz entschieden abzulehnen (JAHRESBERICHT, 1924, s. 6).

14 Sie müssen früher oder später hier in Brasilien ihr Leben aufbauen. Und wenigen ist es vergönnt, im alten Vaterland an der Quelle rein-deutschen Wissens sich zu stärken und bereichern. Fast ausnahmlos werden unsere Schüler genötigt sein, hierzulande ihre Zukunft zu suchen und zu sehen (JAHRESBERICHT, 1924, s. 6).

15 Durante a República de Weimar, os alemães eram denominados cidadãos do Reino Alemão, numa perspectiva de comunidade alemã. 
desenvolvimento intelectual alemão (RELATÓRIO, 1924, p.

$6)^{16}$.

Sob este ponto de vista, a ideia da educação do espírito alemão, na escola, vem atrelada ao desenvolvimento intelectual das disciplinas escolares. A escola garante a questão do ensino, da aprendizagem do conhecimento e do Deutschtum. Mas quem garante a educação do espírito alemão? A situação peculiar da Deutsche Schule urbana Collegio Allemão de Pelotas é fragmentária em relação à educação do espírito alemão. Por tratar-se de uma escola pequena, que enfrenta dificuldades financeiras e tem em seu corpo discente alunos que não falam a língua alemã, no caso os luso-brasileiros, e de outras nacionalidades, de certa forma, esse fato requer uma atenção maior dos professores para atender esses alunos, o que pode parecer um desvio de objetivo da instituição. Isso é uma via de mão dupla, pois a continuidade da instituição também depende financeiramente desses alunos. Mas o diretor direciona seu olhar para a questão dos pais dos alunos teuto-brasileiros. E para que a escola atinja a meta da educação dos princípios do espírito alemão, que também é uma educação moral, necessita, vitalmente, da cooperação e da presença desses pais, junto aos filhos, na direção da realização dos propósitos da escola e, especialmente, cultivando a língua alemã nas famílias.

$\mathrm{O}$ diretor faz uma crítica muito perspicaz à situação do idioma alemão, que deveria ser falado cotidianamente nos lares de teutobrasileiros: "Se o idioma falado na família não for o alemão, então,

16 Daraus folgt dass die Deutsche Schule nicht danach streben kann, ihre Zöglinge, soweit sie in Brasilie geboren sind und dort bleiben wollen - also die überwiegende Mehrzahl - zu künfigten deutschen Staatsbürgern heranzubilden, selbst wenn sie vom Vater her Reichsangehörige gelten. Wer solche Erziehung wünscht, muss seine Kinder in jungen Jahren nach Deutschland schicken [...], und verschliesst ihnen damit unter Umständen die Möglichkeit nach Brasilien zurückzukehren. Die Deutsche Schule in Brasilien kann also nur, wie die rein brasilische Schule, künftige brasilische Staatsbürger erziehen, aber sie gibt ihnen zugleich das Erbe der deutschen geistigen Entwicklung mit auf den Weg (JAHRESBERICHT, 1924, s. 6). 
não precisamos de uma escola alemã” (RELATÓRIO, 1924, p. 6) 17. O diretor argumenta que a escola, não tem condições de fazer com que os alunos se familiarizem com o idioma de seus antepassados se esse não for cultivado nas famílias. Avalia a questão do tempo de permanência dos alunos na escola que é, consideravelmente, muito menor do que o tempo que eles ficam nos lares: "Por esta razão, senhores pais: a personalidade alemã e o espírito alemão devem ser nutridos principalmente na casa da família" (RELATÓRIO, 1924, p. 7) ${ }^{18}$. O diretor, conclui suas palavras relembrando a dupla missão da escola alemã no exterior - no caso a Deutsche Schule urbana Collegio Allemão de Pelotas - que é ministrar uma educação alemã em consonância com as leis educacionais do solo em que estiver instalada, e para tal, a família é condição sine qua non.

Se a família trabalhar neste sentido, a conexão com a escola é criada, então, o sangue vivo flui para as instituições de ensino, e nós professores podemos examinar com os pais, que o espírito alemão pode ser aplicável às necessidades das crianças, nas formas que o tornam efetivo, aqui no Brasil, a pátria de nossos filhos. As escolas alemãs no Brasil, apresentam uma nova fase de seu desenvolvimento, por um lado, devido à sombria situação da Alemanha, por outro lado, pela poderosa onda de imigração alemã no Brasil. As escolas alemãs no estrangeiro terão que provar que têm a força para cumprir o seu objetivo declarado: a educação alemã, em conformidade com os requisitos e necessidades do país em cujo solo, acima de tudo, são abrigadas as crianças (RELATÓRIO, 1924, p. 7) ${ }^{19}$.

17 Ist die Familiensprache nicht deutsch, dann brauchen wir auch keine Deutsche Schule zu unterhalten. (JAHRESBERICHT, 1924, s. 6).

18 Darum ihr Eltern: Deutsche Eigenart und Deutsche Geistesart muss in erster Linie im Elternhaus gepflegt werden (JAHRESBERICHT, 1924, s. 7).

19 Wirkt die Familie in diesem Sinne, dann ist der Zusammenhang mit der Schule geschaffen, dann strömt lebendiges Blut in die Unterrichtsanstalten hinein, und wir Lehrer können im Verein mit den Eltern prüfen, was für die Bedürfnisse der Kinder anwendbar ist, wir können den deutschen Geist in die Formen giessen, die ihn hier in Brasilien, dem Vaterland unserer Kinder, wirksam machen. Die deutschen Schulen in Brasilien stehen, wie uns scheinen will, vor einem neuen Abschnitt ihrer Entwicklung, der einmal durch die trostlose Lage Deutschlands, zum andern durch die mächtige Welle deutscher Einwanderung in Brasilien bedingt wird. Die Deutschen Auslandschulen werden beweisen müssen, dass sie 
Medidas destinadas à manutenção do idioma alemão foram usuais dentro da instituição, pois como é sabido o domínio e a utilização da língua é um dos princípios fundamentais da constituição de uma identidade étnica que estava sendo formada na ambiência escolar. Nota-se aqui, neste período, um claro antagonismo com as políticas de Nacionalização do Ensino no Brasil que, em última instância, tinham como meta justamente eliminar qualquer ensino em língua estrangeira. Esta tensão, somente aumentou até a deflagração do processo de nacionalização institucionalizado e autoritário, com o fito de inibir qualquer comportamento disfuncional neste sentido. Esta circunstância paradoxal revela as situações especiais das escolas alemãs no exterior, que requeriam comportamentos e atitudes compatíveis com as diversas nuances que as diretrizes dos países em que estavam instaladas, exigiam.

É visível que o grau de interferência direta ou indireta de instituições germânicas era bastante forte e explícito. E uma delas se dava na escola. Assim, por exemplo, no Relatório (1925), pela frequente presença de professores alemães, pode-se perceber como era complicada a constituição do corpo docente da instituição:

O Conselho esperava que, após a nomeação de dois professores da Alemanha - Srs. Lysander Fischer de Dresden e Albrecht Tabor de Berlim - no início de 1924, a mudança no corpo docente de nossa escola fosse sanada. Infelizmente, o Sr. Lysander Fischer foi forçado a parar de trabalhar na nossa escola em julho, após um período de 1 ano e meio. Em seguida contratamos uma professor substituta, a senhorita Gertraud Riezler, que a tempo assumiu as aulas sem maiores distúrbios. Para substituir a senhorita Gertrud Riezler, que ensinou seis meses, virá o Sr. Hermann Hettenhausen de Fulda para o início do novo ano escolar (RELATÓRIO, 1925$, p.4 $)^{20}$.

die Kraft haben, die ihnen gestellte Aufgabe zu erfüllen: eine Deutsche Erziehung im Einklang mit den Anforderungen und Bedürfnissen des Landes, auf dessen Boden sie stehen, das vor allen Dingen die Heimat der Kinder ist (JAHRESBERICHT, 1924, s. 7).

${ }^{20}$ Der Vorstand hatte erwartet, dass nach der Anfang 1924 erfolgten Anstellung zweier Lehrer aus Deutschland - der Herren Lysander Fischer aus Dresden und 
A rotatividade dos professores dentro da Deutsche Schule Collegio Allemão de Pelotas, nos últimos anos, indica uma instabilidade. Provavelmente a ação de contratação e demissão de professores, da Diretoria da Sociedade Escolar Alemã, não estivesse relacionada ao grau de satisfação ou insatisfação com o trabalho dos professores, mas ligada a outros fatores, como, por exemplo, a inserção de professores que vinham da Alemanha, nomeados, ou indicados pelas Sociedades de Apoio aos Alemães no Exterior, que também permaneciam pouco tempo no educandário. Cabe questionar: por que e para que vinham? Por outro lado, a troca constante de professores impedia a formação de um grupo docente coeso e forte, capaz de dar outros rumos à instituição.

Estes problemas parecem indicar que a escola constituía-se em um meio utilizado pelas Sociedades de Apoio aos Alemães no Exterior para determinadas pessoas que, após estagiar na escola passavam a desempenhar outras atividades no País. Este é um processo que precisa ser melhor investigado.

Em 1925 ocorreu mais uma visita de autoridades alemãs, conforme o relatório desse ano.

A visita do enviado alemão, Vossa Excelência Knipping, causou grande alegria, não só em torno da colônia alemã de nossa cidade, mas também em nossa escola. As horas passaram rápidas na companhia do representante da nossa antiga pátria, o cônsul alemão. Também esteve entre nós, o Sr. Dr. Dähnhardt de Porto Alegre, pelo que sentimos uma honra e alegria especiais (RELATÓRIO, 1925, p. 4) ${ }^{21}$.

\footnotetext{
Albrecht Tabor aus Berlin - der den Unterricht störende Wechsel im Lehrkörper unserer Schule behoben sein würde. Leider wurde Herr Lysander Fischer gezwungen, im Juli nach einer 1 1/2 jähriger Tätigkeit seine Arbeit an unserer Schule einzustellen. Da wir in Fräulein Gertraud Riezler sogleich Ersatz fanden, so erlitt der Unterricht keine wesentliche Störung. Für Fräulein Gertrud Riezler, die vertretungsweise sechs Monate unterrichtete, wird im neuen Schuljahr Herr Hermann Hettenhausen aus Fulda eintreten (JAHRESBERICHT, 1925, s. 4).

${ }^{21}$ Grosse Freude löste der Besuch des Deutschen Gesandten, Exzellenz Knipping, nicht nur in der ganzen Deutschen Kolonie unserer Stadt, sondern auch in
} 
Da mesma forma observa-se, mais uma vez, a reiterada prática de doação de material didático e livros de literatura alemães efetuados pelo consulado alemão. Os livros recebidos da Embaixada Alemã e do Consulado Alemão, num total de 22 volumes, perfizeram 27,5\% das doações para a biblioteca da escola e têm uma relação direta com a visita do cônsul alemão à escola, constituindo-se em uma resposta à expectativa do diretor da escola que redunda no apoio à formação do antigo pensamento e sensibilidade alemães.

$O$ processo de retroalimentação entre a Verein für das Deutschtum im Ausland (V.D.A.), (Sociedade de Apoio ao Deutschtum no Exterior) e a escola manteve-se constante, o que revela o grau de interdependência mútua das duas instituições. Assim, por exemplo, em 1933, com a escola sob a direção do professor Hans Nagel, há evidências da ação da V.D.A., no estado, através da presença da senhorita M. Bauermeister, diretora da instituição, que algumas vezes em "suas viagens de estudos pelo Rio Grande do Sul” ${ }^{22}$, visitou a escola. Dessas visitas resultou uma parceria de apadrinhamento daquela instituição em relação ao educandário pelotense. Segundo o Relatório de 1933:

Após o seu retorno, ela e o grupo do V.D.A. apadrinharam nossa escola. Como resultado deste trabalho, livros de escola modernos, caixas com livros muito úteis, e até mesmo dinheiro poderiam ser disponibilizados para nós, todas as coisas muito proveitosas para nós, algumas das quais já chegaram, enquanto o restante espera para ser trazido por amigos (RELATÓRIO, 1933, p. 7) 23.

unserer Schule aus. Die kurze Stunde, die der Vertreter unseres alten Vaterlandes im Verein mit dem Deutschen Konsul. Herrn Dr. Dähnhardt aus Porto Alegre, unter uns verweilte, haben wir als eine besondere Ehre und Freude empfunden (JAHRESBERICHT, 1925, s. 4).

22 [...] ,ihrer Studienreise durch Rio Grande do Sul“ (JAHRESBERICHT, 1933, s. 7).

23. Nach ihrer Rückkehr hat sie mit ihrer V.D.A. Gruppe die Patenstelle zu unserer Schule übernommen. Als Ergebnis dieser Arbeit konnten unserer Schule modern Fibeln, Kisten mit auesserst brauchbaren Büchern und sogar ein Geldbetrag zur Verfügung gestellt werden, alles für uns sehr nützliche Sachen, von denen schon ein Teil eingetroffen ist, während der Rest darauf wartet, von Bekannten mitgebracht zu werden (JAHRESBERICHT, 1933, s. 7). 
Além destas contribuições houve uma troca de correspondência relativamente intensa entre os alunos da escola pelotense e a Real Schule Alemã de Lubeckertorfeld, de Hamburgo, numa espécie de reconhecimento de irmandade. Também por intermédio de outro diretor do V.D.A., Sr. Walter Weber, de Berlim, houve a mesma associação com a comunidade escolar de Charlottenburg. Esta relação de fraternidade redundava não poucos dividendos financeiros para a Deutsche Schule Collegio Allemão de Pelotas, como bem aponta o diretor Hans Nagel ao enfatizar seus agradecimentos à "Srta. Bauermeister por seus esforços e trabalho, especialmente pela boa noite de sucesso do V.D.A., que ela organizou com seus alunos em benefício de nossa instituição, em Hamburgo" (RELATÓRIO, 1933, p. 7)24.

\section{Considerações finais}

A questão das inserções que os colaboradores provenientes da Verein für das Deutschtum im Ausland (V.D.A.), (Sociedade de Apoio ao Deutschtum no Exterior), tiveram em relação à Sociedade Escolar Alemã, mantenedora da Deutsche Schule urbana Collegio Allemão de Pelotas, precisa ser vista com muito cuidado. A análise dos diversos relatórios onde são publicados os balancetes anuais de Receita e Despesa (RELATÓRIO, 1923; RELATÓRIO, 1924; RELATÓRIO, 1925), elucida que a escola era deficitária para com a Sociedade Escolar Alemã. Manifestadamente, isto se evidencia ao identificar-se que a receita proveniente do pagamento dos alunos não cobria, na maioria dos anos, os custos operacionais da escola.

Ademais uma outra faceta que também precisa ser estudada com atenção é a contribuição advinda da Alemanha. Essa, na verdade,

24 Ich danke an dieser Stelle Frl. Bauermeister nochmals für ihre Mühen und Arbeit, besonders aber für den gut gelungenen V.D.A. - Abend, welchen sie mit ihren Schülerinnen zu Gunsten unserer Anstalt in Hamburg veranstaltete (JAHRESBERICHT, 1933, s. 7). 
tinha muitas fontes que nem sempre convergiam doutrinária e ideologicamente. Embora, por vezes, englobassem uma ideia mais ampla, no sentido de contribuir para a permanência do Deutschtum em terras estrangeiras, por outro lado, frequentemente decorriam de outras perspectivas como a religiosa propriamente dita. Isto é, as eventuais vinculações da escola com determinadas igrejas luteranas alemãs, ou mesmo sínodos alemães, poderiam implicar apenas uma conotação de cunho religioso e que, pelo menos, não diretamente, estavam associadas a interesses político-doutrinários. Esta correlação, evidentemente, por vezes, ocorria mas a partir dos dados não há como estabelecer indicadores precisos de sua existência.

Outrossim, no caso de instituições diretamente interessadas em assistir as comunidades alemãs no exterior há indícios de que pela própria natureza das mesmas havia uma vinculação maior no sentido de estimular a gênese ou manutenção de um determinado Deutschtum que respondesse aos interesses do estado alemão. No caso em análise, pelo largo período de 40 anos investigados, sabe-se que as diretrizes ideológicas da Alemanha passaram por muitas transformações. Não se deve esquecer que neste período tivemos não somente a consolidação da Alemanha como Estado Nacional, como também, entre outros eventos, a Primeira Guerra Mundial e suas consequências que não deixaram de repercutir em comunidades germânicas no exterior, como a da região em estudo. De maneira que é importante perceber que houve um processo e um projeto de integração entre instituições alemãs e instituições teuto-brasileiras no sentido de estabelecerem-se vínculos de apoio mútuo compatíveis com os objetivos e diretrizes de todos os envolvidos.

Particularmente, após à Primeira Guerra Mundial, proliferaram na Alemanha organizações preocupadas em financiar e apoiar as minorias alemãs no estrangeiro tanto em termos culturais, como em termos econômicos. Muitas delas decorrentes do caráter nacionalista que se estabeleceu neste período, como também algumas com claro viés pan-germanista de cunho imperialista. 
É importante perceber que diferentemente de outras regiões de colonização do Rio Grande do Sul, onde o elemento alemão era uma presença majoritária, no caso da região sul, as comunidade alemãs constituíram-se propriamente em enclaves étnicos e, no caso em particular, torna mais desafiador o papel desempenhado pela Sociedade Escolar Alemã de Pelotas em manter uma Deutsche Schule com um número relativamente reduzido de membros.

A escola não era evidentemente algo isolado da comunidade alemã da cidade. Ao contrário o que se observa é que ela era um instrumento frequentemente utilizado no sentido de plasmar na consciência coletiva da mesma os ideais e as concepções que seus mantenedores entendiam como legítimas representações da identidade alemã. De modo geral em ambientes alemães como o clube Germânia, que congregava esta pequena burguesia étnica, a escola frequentemente se fazia presente com seu coro e seu grupo de teatro, com performances merecedoras de muitos aplausos (RELATÓRIO, 1933).

Para atingir este desideratum, várias foram as ações encaminhadas através dos visitantes da Verein für das Deutschtum im Ausland (V.D.A.), (Sociedade de Apoio ao Deutschtum no Exterior), como o envio de livros, material didático e professores para a Deutsche Schule urbana Collegio Allemão de Pelotas, bem como o incentivo à correspondência entre alunos brasileiros e alemães. O objetivo destas visitas era dimensionar e conferir até que ponto o projeto educacional alemão prosperava nesse educandário, com vistas à manutenção do Deutschtum, que mesclava elementos do nacionalismo alemão vigente, à cultura escolar dessa Deutsche Schule, em tempos de Nacionalização do Ensino no Brasil.

\section{Referências}


ANJOS, M. H. Estrangeiros e Modernização: a cidade de Pelotas no último quartel do século XIX. Pelotas: UFPel, 2000.

ARENDT, I. C. Representações de Germanidade, Escola Professor na Allgemeine Lehrerzeitung für Rio Grande do Sul (Jornal Geral para Professores no Rio Grande do Sul). Tese, Universidade do Vale do Rio dos Sinos, São Leopoldo, 2005.

BURKE P. O que é História Cultural? 2 ed. Rio de Janeiro: Zahar, 2008.

CORSETTI, B. Controle e Ufanismo: A Escola Pública no Rio Grande do Sul (1889/1930). Tese, Universidade Estadual de Campinas, Campinas, 1998.

ESTATUTOS DO COLLEGIO ALLEMÃO DE PELOTAS. Deutscher Schulverein Pelotas. Pelotas: 1915.

GRÜTZMANN, I. O Carvalho entre palmeiras: representações e estratégias identitárias no germanismo. História Unisinos, 7, 8, páginas 69-115, 2003.

JULIA, D. A Cultura Escolar como Objeto Histórico. Revista Brasileira de História da Educação, 1, 9-44, 2001.

KOLLING, N. B. Educação e Escolas em Contexto de Imigração Pomerana no Sul do Rio Grande do Sul - Brasil. Dissertação, Universidade Federal de Pelotas, Pelotas, 2000.

LONER B. A. Construção de classe: operários de Pelotas e Rio Grande (1888-1930). Pelotas: UFPel, 2001.

MAGALHÃES, M. O. Opulência e Cultura na Província de São Pedro do Rio Grande do Sul: um estudo sobre a história de Pelotas (18601890). Pelotas: UFPEL, 1993.

NAGLE, J. (2001). Educação e Sociedade na Primeira República. 2 ed. Rio de Janeiro, RJ: DP\&A, 2001.

NÚÑES SEIXAS, X. M. El Nacionalismo Radical Alemán y la cuestión de las minorias nacionales durante la República de Weimar (19911933). Studia Historica. Historia Contemporánea, 12, 259-285, 1994. PAIVA, V. P. Educação popular e educação de adultos: contribuição à história da educação brasileira. São Paulo: Edições Loyola, 1973. REIS FILHO, C. A Educação e a Ilusão Liberal. São Paulo: Cortez, 1981.

RELATÓRIO de 1913. Jahresbericht der Deutschen Schule zu Pelotas. Pelotas: Buchdruckrei Deutsche Wacht, 1913.

RELATÓRIO de 1921. Jahresbericht des Vereins Schule Pelotas. Porto Alegre: Buchdruckrei von Germano Gundlach \& Comp., 1921. 
RELATÓRIO de 1923. Jahresbericht der Deutschen Schule zu Pelotas. In Zum 25 jährigen Bestehen der Deutschen Schule zu Pelotas, 18981923. Rio Grande: Livraria Rio-Grandense, 1924.

RELATÓRIO de 1924. Jahresbericht der Deutschen Schule zu Pelotas. RELATÓRIO de 1925. Jahresbericht der Deutschen Schule zu Pelotas. RELATÓRIO de 1933. Jahresbericht der Deutschen Schule Pelotas. Pelotas, Rio Grande: Off. Typ. da Liv. Commercial, 1933.

RIBEIRO, M. L. S. História da Educação Brasileira: a organização escolar. 14 ed. Campinas: Autores Associados, 1995.

RINKE, S. Der letzte freie Kontinent: Deutsche Lateinamerikapolitik im Zeichen transnationaler Beziehungen, 1918-1933. Stuttgart: Heinz, 1996.

SAVIANI, D. Escola e Democracia. 35 ed. São Paulo: Autores Associados, 2002.

SIMON, A. Deutsche Evangelische Gemeinde Pelotas (Rio Grandenser Synode) 1888-1938 Zum 50=jährigen Jubiläum (18881938). São Leopoldo: Druck von Rotermund \& Cia, 1938.

WERTHEIMER, F. Von deutschen Parteien und deutschen Führern im Ausland. Berlin: Zentral-Verlag Gmbh, 1927.

Recebido em 14 de abril de 2019. Aprovado em 02 de maio de 2019. 